\title{
Scenedesmus obliquus: A Potential Natural Source for Cosmetic Industry
}

\section{Sevilay Cengiz Sahin (iD*,1}

\author{
${ }^{1}$ Department of Molecular Biology and Genetics, Faculty of Science and Art, Pamukkale University, Denizli, \\ Turkey
}

\begin{abstract}
Skin is the largest organ of our body and it protects interior organs against several environmental factors. Hyperpigmentation problem occurs as a result of abnormal melanin accumulation in the skin. A considerable amount of world's population uses skin whitening products. It is known that various algaederived secondary metabolites play an important role in skin problems. Therefore, the tyrosinase inhibitory activities of $S$. obliquus ethanol and water extracts were evaluated in the present study. Tyrosinase activity was determined spectrophotometrically at $492 \mathrm{~nm}$. The ethanol extract showed the higher inhibitory activity on tyrosinase enzyme $\left(\mathrm{IC}_{50}: 0.0270 \mathrm{~g} / \mathrm{mL}\right)$ than water extract $\left(\mathrm{IC}_{50}: 0.2882 \mathrm{~g} / \mathrm{mL}\right)$. This result may have stemmed from the vanillic, ferulic acid and rutin components that were identified by RP-HPLC only in the ethanol extract.
\end{abstract}

\section{ARTICLE HISTORY}

Received: February 10, 2019

Revised: March 15, 2019

Accepted: March 22, 2019

\section{KEYWORDS}

Scenedesmus obliquus,

Cosmetics,

Enzyme Inhibition,

Hyperpigmentation,

Tyrosinase

\section{INTRODUCTION}

Hyperpigmentation and solar lentigines lead to the formation of dark spots on the skin and these spots constitute an important aesthetic problem for many people. These spots may also occur as a result of pregnancy, liver disease, Addison's disease and etc [1]. Although several methods such as chemical peeling, laser treatment, and so on can be used in order to reduce hyperpigmentation problem, the most common treatments are the topical treatments that target the inhibition of tyrosinase enzyme [2,3].

Tyrosinase enzyme (EC 1.14.18.1) plays a key role in melanin synthesis. Since melanin pigment is an important component of our body, both the abnormal loss and the accumulation of this pigment can cause serious disorders. Although hyperpigmentation problem is the most known problem caused by the accumulation of this pigment, there are more serious disorders such as neurodegeneration associated with Parkinson's disease and skin cancer related to this complication. Reducing melanin amount by inhibiting tyrosinase enzyme is an effective method to prevent above related illnesses [4].

Numerous tyrosinase inhibitors have been identifed up to date, but only a few of them are labelled as safe and effective ones. Although hydroquinone, arbutin and kojic acid are the well-

${ }^{*}$ CONTACT: Sevilay CENGIZ SAHIN $₫$ scengiz@pau.edu.tr D Department of Molecular Biology and Genetics, Faculty of Science and Art, Pamukkale University, 20070, Denizli, Turkey 
known tyrosinase inhibitors, the use of all these inhibitors is limited due to their side effects. For example, hydroquinone is banned in the European Union and can only be used up to $2 \%$ in any formulation in USA. Arbutin is a pro-drug of hydroquinone and in the mode of action of arbutin, a hydroquinone release is formed. Therefore, The European Union Scientific Committee on Consumer Products-2008 [5] emphasized that the use of arbutin in cosmetic products is unsafe. Moreover, although The European Scientific Committee on Consumer Safety-2012 [6] specifies the use of kojic acid at the concentrations up to $1 \%$ in cosmetic products is safe, the use of this compound has been forbidden in many countries due to its serious side effects $[3,7,8]$. Therefore, effective natural tyrosinase inhibitors which are believed to be more reliable and safe attract more attention compared to synthetic counterparts.

Microalgae species with their high spectrum of biodiversity present an important source of biomolecules. Microalgae species are becoming an important part of daily life day by day as these biomolecules find applications in many sectors such as food, cosmetic, medicine, energy and etc $[9,10]$. In addition to the unnecessity of agricultural lands, the rich phytochemical content with various modifications based from cultivation medium makes these species unique sources for industrial applications [8]. Besides these general properties, S. obliquus species was chosen in the present study as a result of its specific features such as high growth rate, high tolerance to environmental change, having a rich content of amino acids, polyunsaturated fatty acids, vitamins and minerals. In this context, the present study was carried out to investigate the potential tyrosinase inhibitory effects of $S$. obliquus extracts.

\section{MATERIAL AND METHODS}

\subsection{Chemicals}

Tyrosinase, L-3,4-dihydroxyphenylalanine (L-DOPA), $\mathrm{KH}_{2} \mathrm{PO}_{4}-\mathrm{K}_{2} \mathrm{HPO}_{4}$, bovine serum albumin (BSA), 2,2-diphenyl-1-picrylhydrazyl (DPPH), Folin-Ciocalteu reagent, butylated hydroxytoluene (BHT) and all standard phenolic compounds used (Gallic acid (GA), p-OH benzoic acid, Vanillic acid, Caffeic acid, Syringic acid, p-Coumaric acid, Ferulic acid, Cinnamic acid, Protocatechuic acid, Hesperidin, Naringin, Rutin and Quercetin) were obtained from Sigma Chemical Co. Ethanol, methanol and acetic acid were purchased from Merck Chemical Company. All other reagents used were of analytical grade.

\subsection{S. obliquus Cultivation Conditions}

The $S$. obliquus species (from Ege University, Faculty of Aquaculture) was grown in Bold Basal (BB) medium at $30 \pm 2{ }^{\circ} \mathrm{C}$ and 12 hours light / 12 hours dark photoperiod. Possible contaminations in $S$. obliquus culture were determined by microscopic analysis.

\subsection{Preparation of Extracts from The Dried Biomass}

Following the harvest, the obtained biomass was lyophilized at $-52^{\circ} \mathrm{C}$ (Labconco 7670530 , FreeZone). The lyophilized sample was extracted with ethanol or distilled water for $12 \mathrm{~h}$ in dark at $50^{\circ} \mathrm{C}$ in a temperature controlled shaker (Memmert, SV 1422). The extracts were dried by the removal of ethanol and water solvents by vacuum evaporation or lyophilisation, respectively and the resulting extracts were stored at $-20^{\circ} \mathrm{C}$ until used.

\subsection{Tyrosinase Enzyme Activity Assay and Inhibition Experiments}

Tyrosinase activity was measured in phosphate buffer solutions $(0.05 \mathrm{M}, \mathrm{pH} 6.8)$ by measuring the increase in absorbance related to DOPA quinone formation at $492 \mathrm{~nm}$ [11]. In inhibition experiments, firstly the $S$. obliquus extracts as an inhibitor were incubated with the enzyme solution at $30^{\circ} \mathrm{C}$ for $10 \mathrm{~min}$, then the tyrosinase activity was measured by using the enzyme-inhibitor mixture. The half maximal inhibitory concentration $\left(\mathrm{IC}_{50}\right)$ values were determined from the inhibition $\%$ - extract concentration curve. All experiments were performed in three replications and the results were expressed as mean \pm S.D. 


\subsection{Determination of The Total Phenolic Contents of $S$. obliquus Extracts}

The total phenolic contents of $S$. obliquus extracts were determined according to FolinCiocalteu total phenolics method at $760 \mathrm{~nm}$ [12]. The details of the method were given in my previous scientific report [8].

\subsection{Phenolic Compound Identification by HPLC}

Phenolic compounds were analyzed according to the modified method of Caponio et al. [13] using a reversed phase HPLC system (RP-HPLC, ThermoUltiMate 3000) equipped with a UV-vis photodiode-array detector. The mobile phase consists of a mixture of two solvents, one of them is the acetic acid solution 3\% (A), and the other is methanol (B). The details of the mobile phase gradient conditions were also given in my previous scientific report [8]. The amount of phenolic compounds in the samples were determined according to the calibration curves formed in the same analysis conditions.

\subsection{Determination of The DPPH Radical Scavenging Activities of S. obliquus Extracts}

DPPH free radical scavenging activity of an extract was determined by the measurement of the decrease in absorbance at $515 \mathrm{~nm}$ [14]. BHT was used as a positive control in the present study. The required concentrations of the extract that cause a $50 \%$ decrease in the initial absorbance of DPPH $\left(\mathrm{IC}_{50}\right)$ were identified as the antioxidant activities of the $S$. obliquus extracts.

\section{RESULTS and DISCUSSION}

\subsection{Tyrosinase Inhibitory Activity}

Utilization of safe inhibitors from natural sources in order to control hyperpigmentation is gaining much importance in the last decade. Therefore, the present study focuses on to determine the inhibitory effect of $S$. obliquus extracts on tyrosinase enzyme. The results showed that both water and ethanol extracts of $S$. obliquus inhibited tyrosinase activity in a dose dependent manner (Figure 1,2).

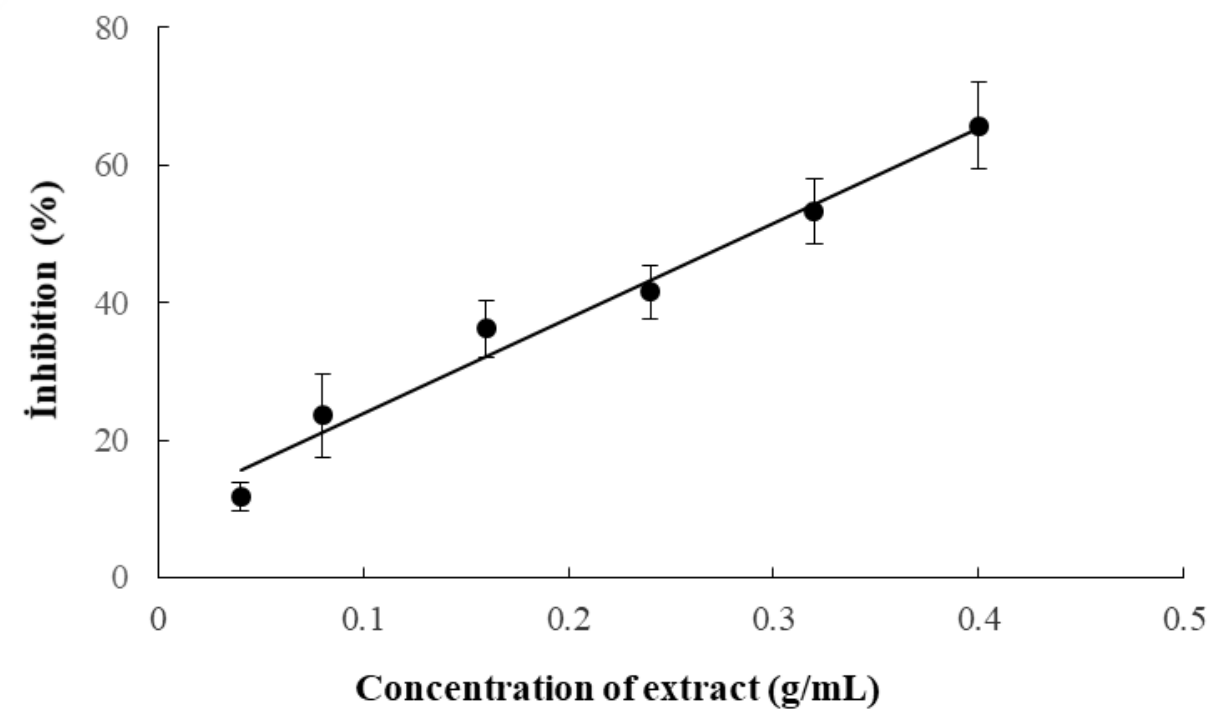

Figure 1. Concentration-inhibition (\%) curve for tyrosinase inhibition by the water extract of $S$. obliquus. $\mathrm{t}=30^{\circ} \mathrm{C},[\mathrm{L}-\mathrm{DOPA}]=3 \mathrm{mM}$. The results are shown as mean $\pm \mathrm{SD}$ of three independent experiment. 


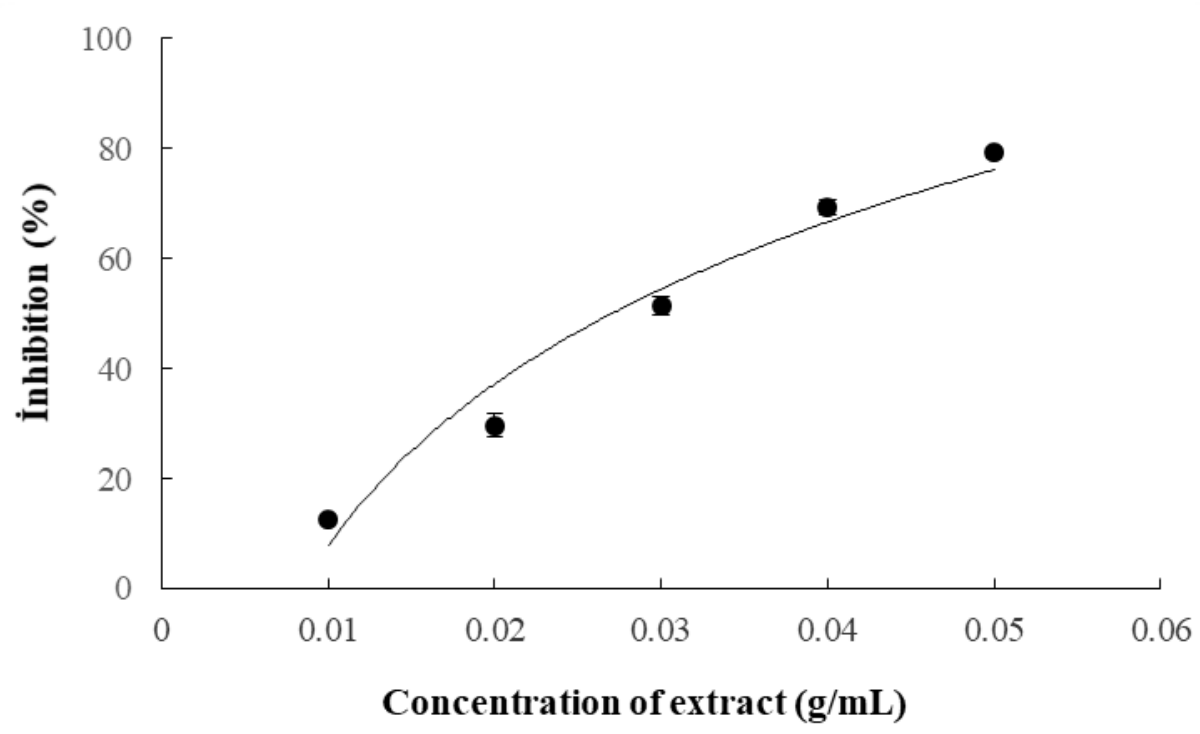

Figure 2. Concentration-inhibition (\%) curve for tyrosinase inhibition by the ethanol extract of $S$. obliquus. $\mathrm{t}=30{ }^{\circ} \mathrm{C},[\mathrm{L}-\mathrm{DOPA}]=3 \mathrm{mM}$. The results are shown as mean $\pm \mathrm{SD}$ of three independent experiments.

The $\mathrm{IC}_{50}$ values of tyrosinase inhibition with $S$. obliquus ethanol and water extracts were found as $0.0270 \mathrm{~g} / \mathrm{mL}$ and $0.2882 \mathrm{~g} / \mathrm{mL}$, respectively. The comparison of $\mathrm{IC}_{50}$ values found in the present study to previously reported ones seems not appropriate due to the variations in assay conditions such as the concentration of substrates, enzymes or the incubation times, etc [15]. Hence, a well-known and commercial tyrosinase inhibitor, kojic acid, was used to make our results more meaningful. The $\mathrm{IC}_{50}$ value of kojic acid was found as $0.00028 \mathrm{~g} / \mathrm{mL}$. It is obvious that the inhibitory effect of kojic acid is higher than the $S$. obliquus extracts. But as indicated above, the use of kojic acid has been forbidden in many countries due to its undesirable side effects. Therefore, $S$. obliquus species used in the present study may serve an alternative material in obtaining safer tyrosinase inhibitors. There are only a few studies in the scientific literature which evaluates the inhibitory effect of microalgae species on tyrosinase enzyme. Fucoxanthine and phloroglucinol derivatives from brown algae and 7-phloroeckol and dieckol from Ecklonia cava have been reported as effective tyrosinase inhibitors [16-19]. The inhibitory effect of a cyanobacteria, Artrosphira platensis, extracts on tyrosinase enzyme were evaluated in a recent study of us. The $\mathrm{IC}_{50}$ values of tyrosinase inhibition with $A$. platensis ethanol and water extracts were reported as $0.0014 \mathrm{~g} / \mathrm{mL}$ and $0.0072 \mathrm{~g} / \mathrm{mL}$, respectively in the related study [8].

\subsection{Total Phenolic Content of S. obliquus Extracts}

Phenolic compounds of many types constitute an important kind of phytochemicals. Hence many researchers try to shed light to their wide range of biological effects in various mechanisms. In addition to having antioxidant, antiviral, antimicrobial, antiproliferative and so on effects, the structure similarities of these compounds to tyrosinase substrate make these compounds more important for this investigation. The positive correlation between the tyrosinase inhibitory activity and the abundance of hydroxyl groups were stated by various researchers [20-23].

The total phenolic content of S. obliquus water and ethanol extracts were determined as $48.0 \mathrm{mg} \mathrm{GAE} / \mathrm{g}$ extract and $22.2 \mathrm{mg} \mathrm{GAE} / \mathrm{g}$ extract, respectively. Stoica et al [24] used water, ethanol and their mixture in order to determine the total phenolic content of Scenedesmus opoliensis. They reported that the highest total phenolic content was found as $151.5 \mathrm{mg}$ GAE/100 g of dry algal biomass for absolute water solvent, and the lowest total phenolic 
content was found as $61.4 \mathrm{mg} \mathrm{GAE} / 100 \mathrm{~g}$ of dry algal biomass for absolute ethanol solvent. Finally, the authors emphasized that the total phenolic content of any substances well correlated with the polarity of solvent. Bulut et al [25] determined the total phenolic content of thermotolerant Scenedesmus species and found that the total phenolic content of prepared extracts increased in order of hexane $(1.13 \pm 0.11 \mathrm{mg} \mathrm{GAE} / \mathrm{g} \mathrm{DW})$, water $(1.97 \pm 0.03 \mathrm{mg} \mathrm{GAE} / \mathrm{g} \mathrm{DW})$, ethyl acetate ( $3.73 \pm 0.65 \mathrm{mg} \mathrm{GAE} / \mathrm{g} \mathrm{DW})$ and ethanol/water $(5.40 \pm 0.28 \mathrm{mg}$ GAE$/ \mathrm{g} \mathrm{DW})$. In an another study of Jerez-Martel et al. [26], the total phenolic content of water and methanol extracts of several microalgae species were determined. The results of the related study presented that the extraction yield of water was higher than that of methanol. The total phenolic content of $S$. obliquus strain was found as $1.94 \mathrm{mg} \mathrm{GAE} / \mathrm{g} \mathrm{DW}$ in another study by Goiris et al. [27]. Actually, the content of phenolic compounds changes as a result of environmental differences due to being secondary metabolites of the defense system of any species [28,29]. Therefore, it is very difficult to compare the results of previous reports.

\subsection{Phenolic Compounds Identification}

Phenolic compounds of $S$. obliquus extracts were identified by RP-HPLC analysis and the results were shown in Table 1.

Table 1. The amount of phenolic compounds (ppm) in the studied extracts of Scenedesmus obliquus.

\begin{tabular}{lcc}
\hline Analysed phenolic compounds & The water extract of S. obliquus & The ethanol extract of S. obliquus \\
\hline Gallic Acid & 12.771 & 1.487 \\
Caffeic Acid & 0.481 & - \\
Vanillic Acid & - & 0.678 \\
P-coumaric Acid & 1.184 & 0.426 \\
Hesperidin & 2.032 & - \\
Ferulic Acid & - & 0.315 \\
Rutin & - & 1.666 \\
Quercetin & 4.750 & 4.711 \\
Cinnamic Acid & 0.550 & 0.566 \\
\hline
\end{tabular}

4 of studied 13 phenolic compounds were found in both extracts. On the contrary, caffeic acid and hesperidin were only found in water extract and vanillic acid, ferulic acid and rutin were only found in ethanol extract. While the main phenolic compound is gallic acid in water extract, it is quercetin in ethanol extract. Besides, very similar amount of quercetin was also found in water extract, too (Table 1).

In another investigation about Scenedesmus strain, two solvent systems were used in the extraction of phenolics. The author detected gallic acid, 4-hydroxy benzoic acid, vanillic acid, caffeic acid, chlorogenic acid and quercetin in ethanol/water extract and gallic acid, benzoic acid, 4-hydroxy benzoic acid, syringic acid, cinnamic acid, coumaric acid, caffeic acid, chlorogenic acid, rosmarinic acid, quercetin and rutin in ethyl acetate extract. It is obvious that the results are well in line with ours. Besides, the amount of gallic acid was significantly higher in polar extract than that of nonpolar extract as in our samples. The opposite was true for the rutin component as in ours, too. The authors determined that there were quite a high amount of quercetin in both extracts and emphasized its importance. This also applies to our results [25].

Vanillic acid, ferulic acid and rutin that were found in ethanol extract may be the main contributors responsible for the higher inhibition or the higher inhibition may be caused from the synergistic effect of all components. Chou et al [30] determined the tyrosinase inhibitory effect of vanillic acid from Origanum vulgare and found the inhibitory activity of this 
compound was higher than the arbutin. Lee et al [31] presented that both ferulic acid ( $\mathrm{IC}_{50}: 0.559$ $\mathrm{mM})$ and caffeic acid $\left(\mathrm{IC}_{50}: 0.037 \mathrm{mM}\right)$ were efficacious tyrosinase inhibitors. The inhibitory effect of rutin on tyrosinase activity was evaluated in another report by Si et al [32]. They found that the $\mathrm{IC}_{50}$ value of tyrosinase inhibition with rutin was found as $6.8 \pm 0.3 \mathrm{mM}$. Besides, the kinetic experiments revealed that rutin inhibited tyrosinase enzyme in a competitive manner by chelating with copper ion at active site.

\subsection{DPPH Radical Scavenging Activity}

DPPH radical scavenging activity method was used in order to determine the antioxidant potential of $S$. obliquus extracts. Since the present study focuses on the evaluation of the potential of $S$. obliquus extracts as a safer source for cosmetic industry, determination of the antioxidant capacity of these extracts are crucial. Undoubtedly, the existence of antioxidants in any product increases its value. The $\mathrm{IC}_{50}$ values of water and ethanol extracts of $S$. obliquus were $2273.7 \mu \mathrm{g} / \mathrm{mL}$ and $938.7 \mu \mathrm{g} / \mathrm{mL}$, respectively. Both of these results were lower than the value of $56.4 \mu \mathrm{g} / \mathrm{mL}$ that was found for the positive control, BHT. Since the phenolic compounds are effective antioxidants, a positive correlation is expected between the total phenolic content and antioxidant activity. Nevertheless, it is not the case for the present results like some previous results in the literature for various algae species. Sabeena Farvin and Jacobsen [33] found the antioxidant capacities of water extracts were higher than that of ethanol extracts of studied seaweeds, although the water extracts have lower total phenolic content. This unexpected result was explained by the possible presence of the other radical scavengers such as pigments, proteins or peptides. Bulut et al [25] highlighted that the high levels of polyunsaturated fatty acids may contribute to the antioxidant capacity of Scenedesmus sp. This observation confirms our result due to the expectation of higher amount of polyunsaturated fatty acids in ethanol extracts than that of water extracts.

\section{CONCLUSION}

Algae are a source of raw materials for many industries such as food, cosmetics, pharmaceuticals, and etc as a result of their biologically active metabolites waiting to be identified. The results of the present study revealed that the extracts of $S$. obliquus species can be used to combat hyperpigmentation problems. In addition to this, semi-synthetic analogues based on the natural ones may be designed in order to cope with the possible problems of natural inhibitors such as cytotoxicity, solubility, absorption, etc. However, more research is needed prior to use these inhibitors for practical applications.

\section{Acknowledgements}

The author is thankful to the Scientific Research Projects and Funds (PAUBAP), Pamukkale University, Turkey and especially the Ministry of Science, Industry and Technology of Turkish Republic for providing financial support.

Orcid

Sevilay CENGIZ SAHIN (Did https://orcid.org/0000-0003-3361-4319

\section{REFERENCES}

[1] Mukherjee, P.K., Biswas, R., Sharma, A., Banerjee, S., Biswas, S., Katiyar, C.K. (2018). Validation of medicinal herbs for anti-tyrosinase potential. Journal of Herbal Medicine, 14, 1-16. Doi: 10.1016/j.hermed.2018.09.002

[2] Briganti, S., Camera, E., Picardo, M. (2003). Chemical and instrumental approaches to treat hyperpigmentation. Pigment Cell and Melanoma Research, 16, 101-110. Doi: 10.1034/j.1600-0749.2003.00029.x

[3] Mann, T., Gerwat, W., Batzer, J., Eggers, K., Scherner, C., Wenck, H., Stäb, F., Hearing, V.J., Röhm, K.H., Kolbe, L. (2018). Inhibition of Human Tyrosinase Requires Molecular 
Motifs Distinctively Different from Mushroom Tyrosinase. Journal of Investigative Dermatology, 138, 1601-1608. Doi: 10.1016/j.jid.2018.01.019

[4] Zolghadri, S., Bahrami, A., Khan, M.T.H., Munoz-Munoz, J., Garcia-Molina, F., GarciaCanovas, F., Saboury, A.A. (2019). A comprehensive review on tyrosinase inhibitors. Journal of Enzyme Inhibition and Medicinal Chemistry, 34, 279-309. Doi: 10.1080/14756366.2018.1545767

[5] Scientific Committee on Consumer Products (2008), Opinion on b-arbutin. Retrieved at 21 November 2017 from: http://ec.europa.eu/health/archive/ph_risk/committees/04_sccp/doc s/sccp_o_134.pdf

[6] Scientific Committee on Consumer Safety (2012), Opinion on kojic acid, Retrieved at 21 November 2017 from http://ec.europa.eu/health/scientific committees/consumer safety/d ocs/sccs o 098.pdf

[7] Gao, H. (2018). Predicting tyrosinase inhibition by 3D QSAR pharmacophore models and designing potential tyrosinase inhibitors from Traditional Chinese medicine database. Phytomedicine, 38, 145-157. Doi: 10.1016/j.phymed.2017.11.012

[8] Cengiz Sahin, S. (2018). The potential of Arthrospira platensis extract as a tyrosinase inhibitor for pharmaceutical or cosmetic applications. South African Journal of Botany, 119, 236-243. Doi: 10.1016/j.sajb.2018.09.004

[9] Ariede, M.B., Candido, T.M., Jacome, A.L.M., Velasco, M.V.R., de Carvalho, J.C.M., Baby, A.R. (2017). Cosmetic attributes of algae - A review. Algal research, 25, 483-487. Doi: 10.1016/j.algal.2017.05.019

[10] Wang, H.D., Chen, C.C., Huynh, P., Chang, J.S. (2015). Exploring the potential of using algae in cosmetics Bioresource Technology, 184, 355-362. Doi: 10.1016/j.biortech.2014. 12.001

[11] Park, Y.D., Lee, J.R., Park, K.H., Hahn, H.S., Hahn, M.J., Yang, J.M. (2003). A new continuous spectrophotometric assay method for DOPA oxidase activity of tyrosinase. Journal of Protein Chemistry, 22, 473-480. Doi: 10.1023/B:JOPC.0000005463.21302.cd

[12] Terpinc, P., Čeh, B., Ulrih, N.P., Abramovič, H. (2012). Studies of the correlation between antioxidant properties and the total phenolic content of different oil cake extracts. Industrial Crops and Products, 39, 210-217. Doi: 10.1016/j.indcrop.2012.02.023

[13] Caponio, F., Alloggio, V., Gomes, T. (1999). Phenolic compounds of virgin olive oil: influence of paste preperation techniques. Food Chemistry, 64, 203-209. Doi: 10.1016/S0308-8146(98)00146-0

[14] Brand-Williams, W., Cuvelier, M.E., Berset, C. (1995). Use of free radical method to evaluate antioxidant activity. Lebensmittel-Wissenschaft und Technologie, 28, 25-30. Doi: 10.1016/S0023-6438(95)80008-5

[15] Lee, S.Y., Baek, N., Nam, T.G. (2016). Natural, semisynthetic and synthetic tyrosinase inhibitors. Journal of Enzyme Inhibition and Medicinal Chemistry, 31(1), 1-13. Doi: 10.3109/14756366.2015.1004058

[16] Kang, H.S., Kim, H.R., Byun, D.S., Son, B.W., Nam, T.J., Choi, J.S. (2004). Tyrosinase inhibitors isolated from the edible brown alga Ecklonia stolonifera. Archives of Pharmacal Research, 27, 1226 - 1232. Doi: 10.1007/BF02975886Thomas, N.V., Kim, S.K. (2013). Beneficial effects of marine algal compounds in cosmeceuticals. Marine Drugs, 11, 146164. Doi: $10.3390 / \mathrm{md} 11010146$

[17] Yoon, N.Y., Eom, T.K., Kim, M.M., Kim, S.K. (2009). Inhibitory effect of phlorotannins isolated from Ecklonia cava on mushroom tyrosinase activity and melanin formation in mouse B16F10 melanoma cells. Journal of Agricultural and Food Chemistry, 57, 41244129. Doi: 10.1021/jf900006f

[18] Heo, S.J., Ko, S.C., Cha, S.H., Kang, D.H., Park, H.S., Choi, Y.U., Kim, D., Jung, W.K., Jeon, Y.J. (2009). Effect of phlorotannins isolated from Ecklonia cava on melanogenesis 
and their protective effect against photo-oxidative stress induced by UV-B radiation. Toxicology in Vitro, 23, 1123-1130. Doi: 10.1016/j.tiv.2009.05.013

[19] Loizzo, M.R., Tundis, R., Menichini, F. (2012). Natural and synthetic tyrosinase inhibitors as antibrowning agents: An update. Comprehensive Reviews in Food Science and Food Safety, 11, 378-398. Doi: 10.1111/j.1541-4337.2012.00191.x

[20] Pei, C.J., Lee, J., Si, Y.X., Oh, S., Xu, W.A., Yin, S.J., Qian, G.Y., Han, H.Y. (2013). Inhibition of tyrosinase by gastrodin: An integrated kinetic-computational simulation analysis. Process Biochemsitry, 48, 162-168. Doi: 10.1016/j.procbio.2012.11.004

[21] Chen, W.C., Tseng, T.S., Hsiao, N.W., Lin, Y.L., Wen, Z.H., Tsai, C.C., Lee, Y.C., Lin, H.H., Tsai, K.C. (2015). Discovery of highly potent tyrosinase inhibitor, T1, with Significant anti-melanogenesis ability by zebrafish in vivo assay and computational molecular modeling. Sci Rep, 5, 7995. Doi: 10.1038/srep07995

[22] Zheng, Z.P., Tan, H.Y., Chen, J., Wang, M. (2013). Characterization of tyrosinase inhibitors in th e twigs of Cudrania tricuspidata and their structure-activity relationship study. Fitoterapia, 84, 242-247. Doi: 10.1016/j.fitote.2012.12.006

[23] Stoica, R., Velea, S., Ilie, L., Calugareanu, M., Ghimis, S.B., Ion, R.M. (2013). The Influence of Ethanol Concentration on the Total Phenolics and Antioxidant Activity of Scenedesmus Opoliensis Algal Biomass Extracts. Revista de Chimie, 64, 304-306.

[24] Bulut, O., Akın, D., Sönmez, Ç., Öktem, A., Yücel, M., Öktem, H.A. (2019). Phenolic compounds, carotenoids, and antioxidant capacities of a thermo-tolerant Scenedesmus sp. (Chlorophyta) extracted with different solvents. Journal of Applied Phycology. Doi: 10.1007/s10811-018-1726-5

[25] Jerez-Martel, I., García-Poza, S., Rodríguez-Martel, G., Rico, M., Afonso-Olivares, C., Gómez-Pinchetti, J.L. (2017). Phenolic profile and antioxidant activity of crude extracts from microalgae and cyanobacteria strains. Journal of Food Quality, 8 pages. Doi: $10.1155 / 2017 / 2924508$

[26] Goiris, K., Muylaert, K., Fraeye, I., Foubert, I., De Brabanter, J., De Cooman, L. (2012) Antioxidant potential of microalgae in relation to their phenolic and carotenoid content. Journal of Applied Phycology, 24, 1477-1486. Doi: 10.1007/s10811-012-9804-6

[27] Connan, S., Goulard, F., Stiger, V., Deslandes, E., Gall, E.A. (2004). Inter specific and temporal variation in phlorotannin levels in assemblage of brown algae. Botanica Marina, 47, 410-416. Doi: 10.1515/BOT.2004.057

[28] Marinho-Soriano, E., Fonseca, P.C., Carneiro, M.A., Moreira, W.S. (2006). Seasonal variation in the chemical composition of two tropical seaweeds. Bioresource Technology, 97, 2402-2406. Doi: 10.1016/j.biortech.2005.10.014

[29] Chou, T.H., Ding, H.Y., Hung, W.J., Liang, C.H. (2010). Antioxidative characteristics and inhibition of a-melanocyte-stimulating hormone-stimulated melanogenesis of vanillin and vanillic acid from Origanum vulgare. Experimental Dermatology, 19, 742-750. Doi: 10.1111/j.1600-0625.2010.01091.x

[30] Lee, H.S., Shin, K.H., Ryu, G.S., Chi, G.Y., Cho, I.S., Kim, H.Y. (2012). Synthesis of Small Molecule-Peptide Conjugates as Potential Whitening Agents. Bulletin Korean Chemical Society, 33, 3004-3008. Doi: 10.5012/bkcs.2012.33.9.3004

[31] Si, Y.X., Yin, S.J., Oh, S., Wang, Z.J., Ye, S., Yan, L., Yang, J.M., Park, Y.D., Lee, J., Qian, G.Y. (2012). An Integrated Study of Tyrosinase Inhibition by Rutin: Progress using a Computational Simulation. Journal of Biomolecular Structure and Dynamics, 29, 9991012. Doi: 10.1080/073911012010525028

[32] Sabeena Farvin, K.H., Jacobsen, C. (2013). Phenolic compounds and antioxidant activities of selected species of seaweeds from Danish coast. Food Chemistry, 138, 1670-1681. Doi: 10.1016/j.foodchem.2012.10.078 